is obtainable through the chain of non-nitrogenous products that I have referred to.

Looking, then, at a case that may happen to be before us, means exist, without bringing in the question of ammonia, for diagnosing whether it belongs to the "alimentary" or whether it has adranced into the "composite" form of diabetes. Upon this point may hinge the view to be taken with regard to the future prospects of the patient, a matter that must be looked upon as of supreme importance. With the foundation I have supplied to work upon I will proceed to consider separately the two forms of the complaint and will, in the first place, speak of the "alimentary" class of case.

(To be continued.)

\section{CONTRIBUTION TO OUR KNOWLEDGE OF URIC ACID SALTS.}

\author{
By F. W. TUNNICLIFFE, M.D., M.R.C.P. Lond., \\ PROFESSOR OF MATERIA MEDICA AND PHARMACOLOGY IN KING'S \\ COILEGE, IONDON ; ASSISTANT PHYSICIAN TO THE VICTORIA \\ HOSPITAL FOR CHILDREN AND TO THE NORTH LONDON \\ HOSPITAL FOR DISEASES OF THE CHEST; \\ AND \\ otTo ROSENHEIM, Ph.D., F.O.S.
}

IN chemical text-books two classes of uric acid $(\bar{U})$ salts are generally described-viz., the neutral $\left(\left(\mathrm{C}_{\bar{n}} \mathrm{H}_{2} \mathrm{~N}_{4} \mathrm{O}_{3}\right) \mathrm{M}_{2}\right.$ or shortly $\left.\mathrm{M}_{2} \overline{\mathrm{U}}\right)$ and acid or biurates $\left(\left(\mathrm{C}_{5} \mathrm{H}_{2} \mathrm{~N}_{4} \mathrm{O}_{3}\right) \mathrm{HM}\right.$ or $H M \bar{U}) .{ }^{1}$ We find, in addition to these in physiological and pathological works, a third class of urates mentioned, having the hypothetical composition of one molecule of biurate loosely combined with one molecule of uric acid, of the general formula $\left(\mathrm{C}_{5} \mathrm{H}_{2} \mathrm{~N}_{4} \mathrm{O}_{3} \mathrm{HM}\right) .\left(\mathrm{C}_{5} \mathrm{H}_{4} \mathrm{~N}_{4} \mathrm{O}_{3}\right)$ or shortly $(\mathrm{MH} \overline{\mathrm{U}}) \overline{\mathrm{U}}$. It is to this last-mentioned class of salts, the so-called quadriurates, ${ }^{2}$ that we have more especially directed our attention. A very important rôle has been ascribed to these salts by Sir William Roberts who regarded them as being in a special sense the physiological salts of uric acid and as "constituting the only form in which uric acid subsists in the living body in the normal state." ${ }^{3}$ Upon this assumption theories important both to the physiologist and physician have been built, but upon examining this subject critically it seemed to us that the actual existence of these salts was by no means established.

The quadriurate hypothesis rests upon results derived from the analysis of normal urinary deposits, and as these have further a wider physiological interest it seemed to us to be advisable to give shortly the history of the work previously done in this connexion.

\section{HISTORY.}

Berzelius was the first to observe the formation of crystals from amorphous urinary deposit under the influence of water. ${ }^{4}$ These crystals he regarded as urate of ammonium. Heintz held the amorphous urinary deposit to consist of a mixture of the urates of ammonium, sodium, calcium, and occasionally potassium and magnesium. ${ }^{5}$ He also pointed out that different sediments yielded different amounts of ash, varying from 2.98 to 8.02 per cent. He regarded the simultaneous precipitation of these three urates as the cause of their amorphous character and the calcium salt as an essential factor in the production of the same. Scherer, in criticising Heintz's paper, concludes that the sediment consists of a mixture of acid urates and free uric acid. ${ }^{6}$ Lehmann confirmed the observation of Berzelius and identified the crystals

1 This nomenclature is misleading in so far as the reactions actually exhibited by the salts in question do not correspond to it. The neutral salts react strongly alkaline and the so-called acid salts, which so far have been accredited with a neutral reaction, have an alkaline one (vide infra).

2 In an earlier article on Piperidine as a Uric Acid Solvent (THE LANcre July 23rd, $1898,0.198$ ) we mentioned that we hed not been (The to convince ourselves of the This con direction.

3. Croonian Lectures, 1892, p. 38.

4 Cehrbuch der Chemie, vol ix 1840,018

5 Annalen der Chemie und Pharmacie, 1845, p. 45. Mïller's Archiv, 1845, p. 230 .

Cannstatt's Jahresberichte, 1845, p. 156. set free by water as uric acid. ${ }^{7}$ Scherer, in a later paper, analysed four samples of urinary deposit and found that it was a complex mixture and that the amount of each of the bases and the sum of all of them were very variable. The next worker in this field was Bence Jones. ${ }^{9}$ He analysed three urinary deposits obtaining different results in each case. He confirmed the important observation of Scherer in that he found in each sample the uric acid present in excess of the quantity required to form biurates with the bases. The excess of this non-combined uric acid was, however, not constant and in no apparent proportion to the amount of combined acid. The proportions were sample No. I. as 1 : 1.72 ; No. II as 1: 0.46 ; No. III. as 1: 1.04. Although the proportions between the free and combined uric acids differed largely in the individual analyses it happened, by mere accident, that the average of free to combined in the three was as $1: 1 \cdot 1$. Bence Jones subsequently proceeded to work out the proportion between the com. bined and free uric acid in the deposits analysed by Scherer. Viewed from this standpoint Scherer's figures gave discordant numbers, as follows:-Sample I., as 1: 2.04 ; II., as $1: 0.17$; III., as $1: 0.42$; and 1V., as $1: 2.08$. Bence Jones gives the average of these proportions as $1: 1 \cdot 1,{ }^{10}$ and does not seem to have attached any importance to this coincidence, but concludes: "It is very evident from these analyses that a mixture of different amounts of urates and uric acid constitutes the amorphous sediment of the urine." In spite of this, however, he seemed impressed that this proportion so "nearly approximated" (sic) to the "proportion hypo. thetically required by a salt whose molecule consisted of one molecule of uric acid combined with one molecule of acid urate." In pursuance of this idea he attempted to demonstrate the formation of such a salt under artificial conditions and succeeded in preparing compounds which were decomposed under the influence of water into biurate and uric acid. He produced, however, very slender evidence of the existence of a third class of uric acid salts, having the constitution of quadriurates, but in spite of this concludes "that quadriurates exist occasionally under natural conditions in amorphous urinary deposits, and can also be made artificially."

The subject remained in this condition until it was taken up by Sir William Roberts. ${ }^{11}$ This observer, while acknowledging the inadequacy of the proof adduced by Bence Jones for the existence of quadriurates, endeavoured to prepare them himself by a modification of Bence Jones's methods. He was unable to demonstrate their presence in the natural amorphous urinary sediment but prepared amorphous urates, using human urine and various saline solutions as solvents for uric acid and to the compounds thus obtained ascribed the constitution of quadriurates. The analyses, however, upon which he relied as proving this composition are from the standpoint of the modern chemist inadequate, as will be shown later. Upon these insufficiently establisbed ddta he proceeded to enunciate an elaborate hypothesis with regard to the presence and transformation of the so-called quadri. urates in the tissues and blood. These views seem to have been more or less accepted and passed into many text-books, ${ }^{19}$ although they have received no experimental confirmation.

The only experimental criticism which we have been able to find is by Pfeiffer. ${ }^{13}$ This observer points out that the substances upon which Roberts founded his quadriurate theory were either sediments (and as such pathological) or of artificial origin, also that in the pathological sediments the presence of quadriurates could not be demonstrated. He himself further demonstrated the presence of phosphates in some of the so-called quadriurates prepared according to Roberts and pointed out that the quadriurates could only ex hypothesi exist in distinctly acid media, which condition does not obtain in the juices and secretions of the body except in the case of the urine and sweat. Minkowski ${ }^{14}$ regards the assumption that uric acid exists in the blood in the form of a quadriurate as " unwarranted." In a recent

7 Lehwbuch der Physiologischen Chemie, vol, ii., p. 355. 8 Cannstatt's Jahresberichte, 1849. We were unable to find this paper in the original; our analyses are quoted from Bence Jones (vide infra)

9 Journal of the Chemical Society, 1862, vol. xv., p. 201. 10 Upon re-calculation it will be found, however, that this proportion is as $1: 1 \cdot 8$.

11 Croonian Lectures, 1892

12 Neubauer and Vogel, Analyse des Harns, 1898 ; Halliburton, Textbook of Chemical Physiology and Pathology, 1891, p. 732; Allen, Chemistry of Urine, 1895, \&c.

Berliner Klinische Wochenschrift, 1894, 913, 934.

14 Leyden's Handbuch der Ernährungstherapie, Band II. 
monograph on uric acid ${ }^{15}$ Schreiber questions the explanatory value of the quadriurate theory as far as concerns the phenomena of gout.

For the sake of clearness we purpose dividing this paper as follows : I. Examination of Sir William Roberts's chemical methods and critical repetition of his experiments. II. Natural and artificial urinary sediments. III. Decomposition by water of substances containing uric acid and urates, and new method of preparing them. IT. Physico-chemical observations on uric acid and its salts and the significance of the same. V. Conclusions.

\section{I.}

Sir William Roberts for the analysis of his so-called quadriurates relies upon the following method, which he terms "water-analysis." 16 The dry deposit was heated to about the boiling point with about 1000 times its weight of distilled water. The uric acid which crystallised out after 48 hours, was filtered off and weighed, the quantity remaining dissolved in the liquid being taken in regard. The filtrate which contained the biurate was decomposed with hydrochloric acid and the uric acid estimated as above. This procedure is open to the following objections. The estimation of uric acid by means of precipitation with hydrochloric acid (Heintz's method) is now obsolete, its inaccuracy and absolute unreliability for scientific purposes having been shown by many investigators. ${ }^{17}$ The quantity of uric acid kept in solution and estimated at 0.0055 gramme per 100 cubic centimetres, although added to the free uric acidthe uric acid separated from the mixture of uric acid and biurate by water-does not 'seem to have been subtracted from the uric acid kept in solution as biurate. As the weigh of substance in 100 cubic centimetres was 0.1 gramme, the error incurred amounts to 5.5 per cent. It is obvious that this error would affect seriously the amount of uric acid calculated as biurate. Further, Sir William Roberts seems to have overlooked the fact that all uric acid salts deposited from solution and dried at $36^{\circ} \mathrm{C}$. (this being the case in his experiments) contain varying quantities of water constitutionally bound, amounting in the case of the magnesium salt to 35.9 per cent. The analyses made by the Croonian lecturer refer to substances dried at blood-heat, and therefore containing (vide infra) relatively high percentages of water. This fact, together with the errors of method mentioned above, seemed in our opinion to necessitate a repetition of his experiments.

We attempted to prepare so-called quadriurates by working under exactly the same conditions as Sir William Roberts, and obtained what, according to him, should correspond to a quadriurate of the following bases: sodium, potassium, ammonium, magnesium, and calcium. The substances were all dried at $36^{\circ} \mathrm{C}$ and subsequently submitted to quantitative analysis, which consisted in estimating the amounts of water, bases, and uric acid. The water was estimated by drying at a temperature of $100^{\circ} \mathrm{C}$. (if not otherwise stated) till the weight was constant. The bases were estimated in the usual manner. In order to obviate the errors by loss, \&.o., attendant upon the ordinary methods of uric acid estimation we determined its amount by nitrogen estimation (no other nitrogenous substances being present) and subsequent calculation. The nitrogen was estimated by Gunning's modification of Kjeldahl's method. ${ }^{18}$ Each substance was examined microscopically with regard to the influence of water upon it.

\section{SODIUMI URATES.}

According to Sir W. Roberts sodium quadriurate is formed from uric acid by the action of the acetates ${ }^{19}$ and dimetallic phosphates ${ }^{20}$ of this base. We prepared different samples by each method, using 3 per cent. and 5 per cent. solutions of the acetate of sodium, and 2 per cent. and 5 per cent. solutions of the phosphate.

A. Salts formed by the acetate method. - These salts were obtained in the following manner. The 3 per cent. and 5 per cent. solutions, as the case might be, were brought to the boiling point and then shaken up for a minute or so with an excess of uric acid, filtered hot, and the filtrate cooled

15 Uber die Harnsizure, Stuttgart, 1899, pp. 107, 108. 16 Loc. cit., p. 18

${ }^{17}$ For complete literature of this subject see Warneke, Dissertation Guttingen, 1808

Zeitschrift fuir Analytische Chemie, 1889, p. 89. The uric acid used hour experiments was absolutely pure, being purified three times by Benseh's methods.

19 Loc. cit., p. 25.

20 Ibid, , p. 85 rapidly on ice. A voluminous precipitate formed at once, the reaction of the liquid being slightly acid. The precipitate was filtered by the aid of a suction pump, washed with dilute and subsequently with absolute alcohol and ether and dried at blood temperature. These various manipulations were performed as quickly as possible. In the case of the 3 per cent. acetate solutions it was found that the waterfree substances consisted almost entirely of uric acid. The first sample contained 99.41 per cent. uric acid to 0.59 per cent. sodium, the second sample contained 98.99 per cent. uric acid to 1.01 per cent. sodium. This fact has already been observed by Lipowitz who demonstrated qualitatively the nature of the precipitate. ${ }^{21}$ In the case of the 5 per cent. acetate solutions the loss of water at $130^{\circ} \mathrm{C}$. was estimated in the substance dried previously at $30^{\circ} \mathrm{C}$. and found to be 8.08 per cent. (Table I.).

The "calculated composition" of the substance at $130^{\circ} \mathrm{C}$ was arrived at by the following method of reasoning. 5.23 per cent. of sodium requires 38.20 per cent. of uric acid to form sodium biurate. $I_{i}^{r}$ this quantity be subtracted from the total amount of uric acid (9071 per cent.) the remainder (52.51 per cent.) represents the free uric acid. The amount of water lost at $130^{\circ} \mathrm{C}$. (as well as retained at that temperature) is in molecular proportion to the sodium biurate corresponding to the sodium found. The same method of calculating was used in the following tables.

Another salt prepared in the same way with a 5 per cent. solution of acetate of sodium gave the following results (Table II.).

$B$. Salts formed by the phosphate method.-According to Sir William Roberts, "solutions of the common dimetallic phosphates of soda, Src., ...... also take up uric acid very freely at blood heat, and the combination formed in this case in the first instance is likewise a quadriurate." ${ }^{22}$ No analytical confirmation of this assumption is to be found. As Sir William Roberts does not give any directions as to the strength of the phosphate solution most suitable for this reaction we made some preliminary experiments on this point, using 1 per cent., 2 per cent., and 5 per cent. solutions. These solntions were treated with an excess of uric acid under constant agitation at blood heat for 20 minutes, filtered and cooled rapidly on ice. In the case of 1 per cent. solutions no immediate precipitation occurred, but took place on slightly acidifying with phosphoric acid, in which case the precipitate consisted of pure uric acid crystals. On another occasion a precipitate formed upon keeping the solution on ice for a considerable time without the addition of phosphoric acid. The precipitate showed under the microscope the characteristic uric acid crystals and was found upon analysis to consist to the extent of 97 per cent. of free uric acid. Similar observations have been made by Lipowitz ${ }^{23}$ and especially by Liebig. ${ }^{21}$ The latter regarded the phosphates as being the agents by which uric acid was kept in solution in the urine.

That pure uric acid is deposited if a solution of biurate of sodium, saturated at the body temperature, be mixed with a solution of monosodium phosphate and cooled, was shown by Voit and Hofmann ${ }^{25}$ and confirmed by Bunge. ${ }^{26}$ The conditions in their experiments are practically the same as those obtaining in our own, in which as the first products of interaction between uric acid and dimetallic phosphate, biurate and monometallic phosphate are formed, these latter reacting again as in the experiments of Voit and Hofmann and Bunge.

We next prepared urates of sodium by digesting 2 per cent. and 5 per cent. solutions of dimetallic sodium-phosphate with excess of uric acid at blood heat in the same way as before. The composition of the substances is shown in Table III.

From the above tables it is evident that neither by the acetate nor by the phosphate method could precipitates be obtained corresponding in composition to the hypothetical quadriurates. In the case of the phosphate method a fact of considerable interest is the constant presence of phosphoric acid in the urates formed. We were also able by the qualitative examination of many other similarly produced substances to demonstrate the presence of phosphoric acid whenever the precipitate was not entirely composed of uric acid. This latter fact, although evidently overlooked by Sir

21 Liebig's Annalen, Band xxxviii., p. 348. 22 Loc. cit., p. 85.

23 Loc eit.

25 Sitzungsberichte der Bayrischen Akademie, 1867, p. 279. Bunge, Lehrbuch, p. 327 
DR. F. W. TUNNICLIFFE AND DR. O. ROSENHEIM: URIC ACID SALTS.

Table I.-Sodium Salt, Acetatw Methon (Lot 1).

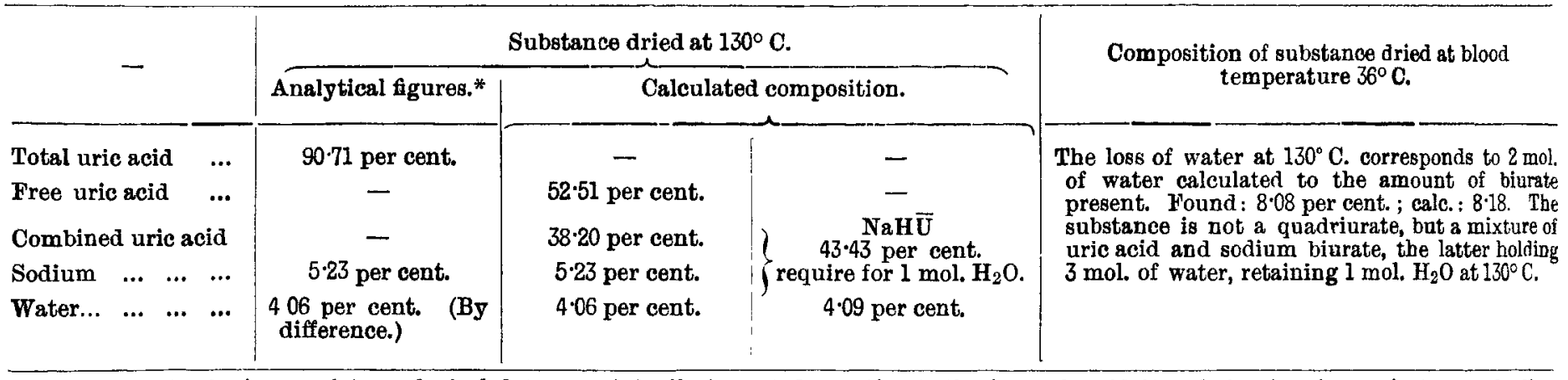

* In order to obtain complete analytical data we originally intended to estimate the free uric acid directly by titration against a standardised piperidine solution (Comp. Brit. Med. Journ. 5, II. 98). But it was found that owing to the solvent action of piperidine on the biurate present piperidine solution (Comp. Brit. Med

Table II.-Sodium Salt, Acetate Method (Lot 2).

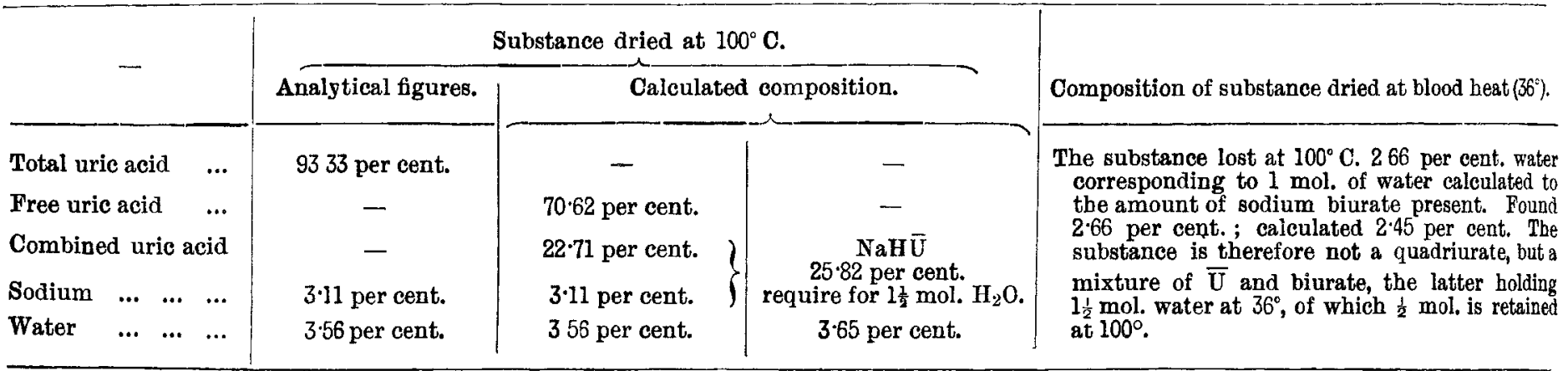

Table III.-Sodium Salts, Phosphate Method.

\begin{tabular}{|c|c|c|c|c|c|c|c|c|}
\hline \multirow{2}{*}{ - } & \multicolumn{2}{|c|}{$\underbrace{\text { Analytical. }}_{\text {figures. }}$} & \multicolumn{4}{|c|}{ Calculated composition. } & \multicolumn{2}{|c|}{$\begin{array}{c}\text { Conclusion concerning the composition of substance } \\
\text { dried at } 36^{\circ} \mathrm{C} .\end{array}$} \\
\hline & $\begin{array}{l}2 \text { per } \\
\text { cent. }\end{array}$ & $\begin{array}{l}5 \text { per } \\
\text { cent. }\end{array}$ & 2 per & cent. & 5 per & cent. & 2 per cent. & 5 per cent. \\
\hline Total uric acid .. & $77 \cdot 13$ & $73 \cdot 25$ & - & - & - & - & The substance is & The substance lost at $100^{\circ} \mathrm{C} .552$ per \\
\hline Free uric acid .. & - & - & $22 \cdot 65$ & - & $22 \cdot 34$ & - & not a quadri- & $\begin{array}{l}\text { cent. of water, corresponding to l mol. } \\
\text { of water, calculated to the amount of }\end{array}$ \\
\hline Combined uric acic & - & - & $54 \cdot 48$ & $\mathrm{NaH} \overline{\mathrm{U}}$ & $50 \cdot 91$ & ( $\mathrm{NaH} \overline{\mathrm{U}}$ & $\begin{array}{l}\text { ture of phosphate } \\
\text { of sodium free }\end{array}$ & $\begin{array}{l}\text { biurate present: Found, } 5.52 \text { per cent; } \\
\text { calculated } 5.45 \text { per cent, The substance }\end{array}$ \\
\hline Sodium $\quad \ldots \quad \ldots \quad \ldots$ & $9 \cdot 71$ & $10 \cdot 85$ & $7 \cdot 46$ & $\begin{array}{l}61.94 \\
\text { require }\end{array}$ & 6.97 & $\begin{array}{l}7.88 \\
\text { quire }\end{array}$ & uric acid, and bi- & is therefore not a quadriurate, but \\
\hline Phosphoric acid .. & $3 \cdot 47$ & $5 \cdot 98$ & - & $\begin{array}{c}\text { for } 1 \frac{1}{2} \\
\text { mol. of } \\
\text { water. }\end{array}$ & - & $\begin{array}{l}\text { for } 1 \frac{1}{2} \\
\text { mol. of } \\
\text { water. }\end{array}$ & $\begin{array}{l}\text { urate of sodium, } \\
\text { the latter hold- } \\
\text { ing } 1 \frac{1}{2} \text { mol. of } \\
\text { water constitu- } \\
\text { tionally bound. }\end{array}$ & $\begin{array}{l}\text { consists of a mixture of phosphate of } \\
\text { sodium, free uric acid, and biurate of } \\
\text { sodium, the latter holding } 1 \frac{1}{2} \mathrm{~mol} \text { of } \\
\text { water, of which } 1 \text { mol. is given off at } \\
100^{\circ} \mathrm{C} \text {. }\end{array}$ \\
\hline Sodium-phosphate & - & - & 6.94 & - & $11 \cdot 96$ & 一 & & \\
\hline Water $\quad \ldots \quad \ldots \quad$.. & - & - & $\begin{array}{c}8 \cdot 47 \\
\text { (By dif- } \\
\text { ference. })\end{array}$ & $8 \cdot 79$ & $\begin{array}{l}7 \cdot 82 \\
\text { (By dif- } \\
\text { ference.) }\end{array}$ & $8 \cdot 17$ & & \\
\hline
\end{tabular}

Table IV.-Potassium Salts, Acetate Method.

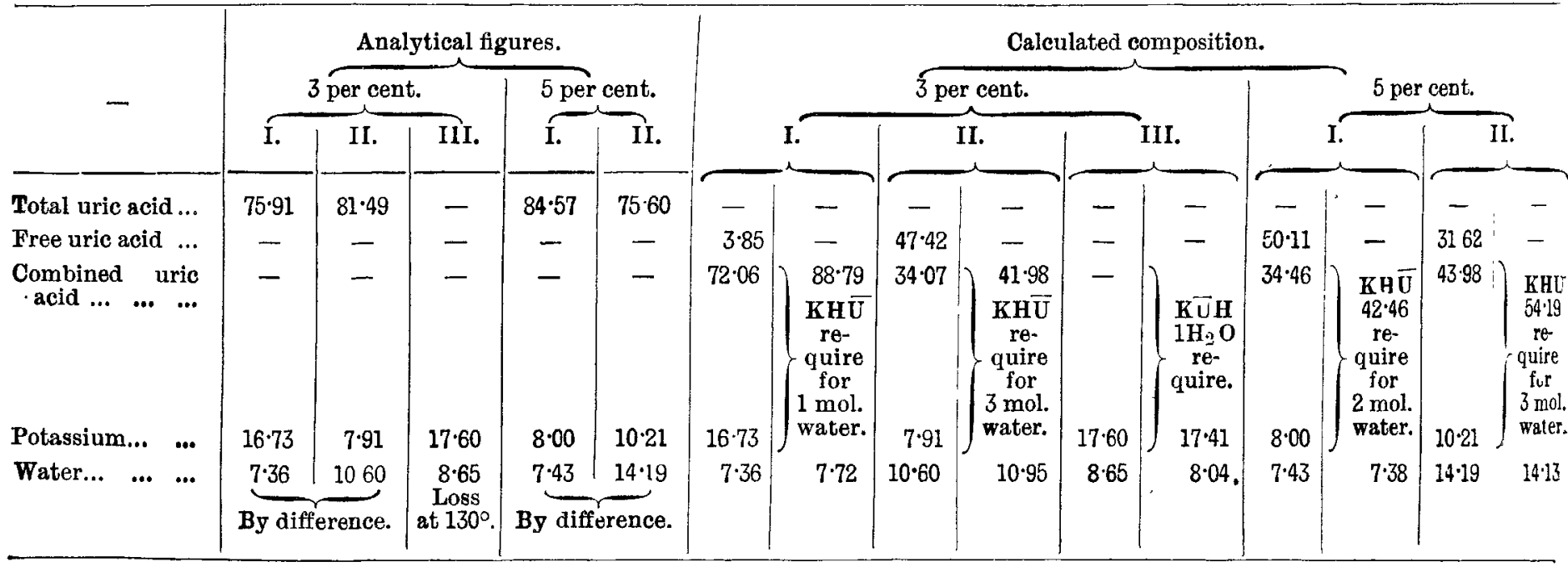

Conclusions concerning the composition of substance dried at $36^{\circ} \mathrm{C}$.

\begin{tabular}{|c|c|c|c|c|}
\hline \multicolumn{3}{|c|}{3 per cent. } & \multicolumn{2}{|c|}{5 per cent. } \\
\hline I. & II. & III. & I. & II. \\
\hline $\begin{array}{l}\text { The substance is nearly } \\
\text { pure biurate of potas- } \\
\text { sium, consisting of } 3 \cdot 85 \\
\text { per cent. uric acid and } \\
96 \cdot 15 \text { per cent. of } \\
\text { biurate, the latter } \\
\text { holding } 1 \text { mol. } \mathrm{H}_{2} \mathrm{O} \\
\text { constitutionally bound. }\end{array}$ & $\begin{array}{l}\text { The substance is not a } \\
\text { quadriurate, but a mix- } \\
\text { ture of uric acid and } \\
\text { biurate, the latter } \\
\text { holding } 3 \text { mol. of } \\
\text { water constitutionally } \\
\text { bound. }\end{array}$ & $\begin{array}{l}\text { The substance is pure } \\
\text { potassium biurate, } \\
\text { holding } 1 \text { mol. of } \\
\text { water constitu- } \\
\text { tionally bound. }\end{array}$ & 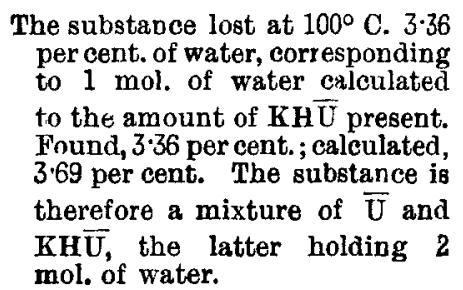 & $\begin{array}{l}\text { The substance is not a } \\
\text { quadriurate but a mix- } \\
\text { ture of uric acid and } \\
\text { biurate, the latter hold- } \\
\text { ing } 3 \text { mol. of water } \\
\text { constitutionally bound. }\end{array}$ \\
\hline
\end{tabular}


William Roberts, was observed as early as 1844 by GoldingBird $^{27}$ and independently by Pfeiffer, ${ }^{28}$ who made some quantitative estimations.

\section{PotASSIUM URATES.}

The potassium salts were prepared in a manner analogous to the sodium compounds, potassium acetate being used. Two strengths of potassium acetate solutions were takennamely, 3 per cent. and 5 per cent. The precipitates were filtered, washed, and dried in the usual way. The analytical results are expressed in Table IV.

From this table it is evident that in no case was a precipitate formed to which the constitution of potassium quadriurate could be ascribed.

\section{AMMONIUM URATE.}

According to Sir William Roberts a quadriurate of ammonia is obtained by the method described below. ${ }^{29}$ The product, however, was not submitted to analysis nor was any further proof of its existence mentioned. Following the directions we prepared the hypothetical quadriurate as follows: 5 grammes of uric acid were boiled in a litre of a 1 per cent. solution of liquor ammonix. The solution was filtered hot and rapidly cooled on ice. An abundant stream of carbonic acid was then passed through it and the precipitate obtained was washed and dried in the usual way. All these manipulations were carried out as rapidly as possible. Table $V$. gives the result of the analysis.

TABLE V.-Ammonium Salt.

\begin{tabular}{|c|c|c|c|c|}
\hline- & & $\begin{array}{l}\text { Analytical } \\
\text { figures. }\end{array}$ & $\begin{array}{l}\text { Calculated for } \\
\text { ammonium } \\
\text { biurate }+ \\
2 \text { mol. } \mathrm{H}_{2} \mathrm{O} \text {. }\end{array}$ & $\begin{array}{l}\text { Calculated for } \\
\text { ammonium } \\
\text { quadriurate. }\end{array}$ \\
\hline Total uric acid & & 76.00 per cent. & 76.02 per cent. & $95 \cdot 18$ per cent. \\
\hline Ammonia ... ... & $\ldots$ & $8 \cdot 27$ & $7 \cdot 69 \quad$, & $4 \cdot 82 \quad$ " \\
\hline Water $\quad \ldots \quad \ldots$ & $\ldots$ & (By difference.) & $16 \cdot 29$ & - \\
\hline
\end{tabular}

As will be seen from this table the salt dried at $36^{\circ} \mathrm{C}$. is not a quadriurate, but ammonium biurate $+2 \mathrm{H}_{2} \mathrm{O}$.

\section{Calcium and Magnesium URates.}

According to Sir William Roberts the quadriurates of calcium and magnesium are prepared in the following manner. ${ }^{30}$ The calcium salt is obtained by dissolving 0.5 gramme of uric acid in 100 cubic centimetres of cold lime water. To the filtered solution acetic acid was added, drop by drop, until neutralisation was approached. An abundant precipitate was then thrown down, which was caught on a filter, washed with rectified spirit, and dried. Magnesium quadriurate was prepared by digesting uric ucid and calcined magnesia both in excess and distilled water at blood heat with frequent agitation for about ten minutes, the mixture was filtered warm, and the filtrate was rapidly cooled under a running tap of cold water. The precipitate was filtered, washed, and dried in the usual manner. In neither case is any analysis given in support of the supposed quadriurate composition of the respective product. We followed exactly Sir William Roberts's directions and prepared two samples of the magnesium and one of the calcium salt. Tables VI, and VII. express the results of the analyses.

TABLE VI.-Magnesium Urates.

\begin{tabular}{|c|c|c|c|c|}
\hline \multirow{2}{*}{-} & \multicolumn{2}{|c|}{ Analytical results. } & \multirow{2}{*}{$\begin{array}{l}\text { Calculated } \\
\text { for magne- } \\
\text { sium biurate } \\
+12 \mathrm{H}_{2} \mathrm{O} \text {. }\end{array}$} & \multirow{2}{*}{$\begin{array}{l}\text { Oalculated } \\
\text { for magne- } \\
\text { sium quadri- } \\
\text { urate. }\end{array}$} \\
\hline & 1. & II. & & \\
\hline Total uric acid... & $\begin{array}{c}\text { Per cent. } \\
61 \cdot 68\end{array}$ & $\begin{array}{c}\text { Per cent. } \\
60 \cdot 10\end{array}$ & $\begin{array}{l}\text { Per cent. } \\
6001\end{array}$ & 96.54 \\
\hline Magnesium ... & $4 \cdot 45$ & 438 & $4 \cdot 05$ & $3 \cdot 46$ \\
\hline \multirow[t]{2}{*}{ Water $\ldots \ldots \quad \ldots$} & 33.87 & 3552 & 35.94 & - \\
\hline & \multicolumn{2}{|c|}{ By difference. } & & \\
\hline
\end{tabular}

It will be seen from the above table that neither of these

$$
\begin{aligned}
& 27 \text { London Medical Gazette, 1844, p. } 685 . \\
& 29 \text { Loc. cit., p. } 27 . \quad \text { Loc. cit. }
\end{aligned}
$$

salts is a quadriurate and that whereas No. II. corresponds $\overline{\mathrm{u}}$

almost exactly to the formula $\mathrm{Mg}+12 \mathrm{H}_{2} \mathrm{O}$, No. I.

$$
\overline{\mathrm{U}}
$$

approaches the required figures very nearly, containing only

\begin{tabular}{|c|c|c|c|c|}
\hline- & $\begin{array}{l}\text { Analytical } \\
\text { results. }\end{array}$ & $\begin{array}{l}\text { Calcu } \\
\text { compo }\end{array}$ & $\begin{array}{l}\text { alated } \\
\text { sition. }\end{array}$ & - \\
\hline Total uric acid & $\begin{array}{c}\text { Per cent. } \\
76.51\end{array}$ & Per cent. & - & The analysis of this \\
\hline Free uric acid & - & $49 \cdot 04$ & - & sists of a mixture of \\
\hline $\begin{array}{r}\text { Combined } \\
\text { uric acid }\end{array}$ & $3 \cdot 29$ & $27 \cdot 47$ & $\begin{array}{l}30.47 \text { per } \\
\text { cent. } \\
\text { calcium } \\
\text { biurate } \\
\text { require } \\
\text { for } 14 \\
\text { mol. } \mathrm{H}_{2} \mathrm{O}\end{array}$ & $\begin{array}{l}\text { biurate, the latter } \\
\text { holding } 14 \text { mol. of. } \\
\text { waterconstitutionally } \\
\text { bound. At } 100^{\circ} \mathrm{C} \text {. it } \\
\text { lost } 12 \cdot 00 \text { per cent. of } \\
\text { water corresponding } \\
\text { to } 8 \text { mol. of water } \\
\text { calculated on the }\end{array}$ \\
\hline Water $\quad .$. & $20 \cdot 20$ & $20 \cdot 20$ & $20 \cdot 72$ & \begin{tabular}{llr} 
present. & \multicolumn{2}{c}{ Calculated, } \\
$11 \cdot 84$ & per & cent.; \\
found, & 12.00 & per \\
cent. & &
\end{tabular} \\
\hline
\end{tabular}
a slight excess of uric acid.

TABLE VII.-Calcium Urate.

II.

Natural and ARtificial URINary Sediments.

So far as we are aware the only analyses approaching to completeness of naturally occurring urinary sediments are those made by Scherer and Bence Jones. ${ }^{31}$ Since the number of these is somewhat scanty and the most recent was made in 1862 we thought it would be advisable to add to their number, especially as we had the opportunity of getting. a constant supply of naturally-occurring deposit from the same person. The quantity necessary for analysis was collected in the following way. The urine directly upon being voided was rapidly cooled and the deposit allowed to settle. It was then filtered off by the aid of a suction pump, washed with alcohol and ether, and dried at $36^{\circ} \mathrm{C}$. The fractions thus collected were mixed ${ }^{32}$ together and kept in a stoppered bottle until sufficient for the purposes of analysis.

\begin{tabular}{|c|c|c|c|c|c|c|}
\hline & & & & $\begin{array}{l}\text { Analytical } \\
\text { numbers. }\end{array}$ & & $\begin{array}{l}\text { Calculated to } \\
\text { water, \&.., free- } \\
\text { substance. }\end{array}$ \\
\hline Uric acid & $\cdots$ & & $\ldots$ & $73 \cdot 40$ & & $95 \cdot 69$ \\
\hline Ammonia & $\ldots$ & $\ldots$ & $\ldots$ & 0.46 & .......... & 0.59 \\
\hline tassiun & $\ldots$ & $\ldots$ & $\ldots$ & $1 \cdot 74$ & .......... & $2 \cdot 26$ \\
\hline dium & $\ldots$ & $\ldots$ & $\ldots$ & 0.23 & .......... & 0.29 \\
\hline Magnesium & $\ldots$ & $\ldots$ & $\ldots$ & 0.06 & ‥ & 0.08 \\
\hline Calcium ... & $\ldots$ & $\ldots$ & $\ldots$ & 0.34 & .......... & 0.44 \\
\hline $\mathrm{O}_{5} \quad \ldots$ & & $\ldots$ & $\ldots$ & 0.48 & ... & 0.63 \\
\hline
\end{tabular}
was obtained. The analysis gave the following results:-

Natural Urinary Sediment.

Water, colouring matter

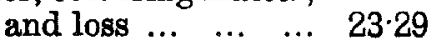

The amount of phosphoric acid present almost exactly corresponds to the amount required to satisfy the calcium (required for 0.63 per cent. phosphoric acid 0.53 per cent. calcium ; found 0.44 per cent.). If the amount of uric acid be calculated which is required to form biurates with the remaining bases it will be found to be 19.33 per cent., this subtracted from the total uric acid leaves 7636 per cent. free uric acid. It is therefore evident that the sediment in question consisted to a large extent of free uric acid mixeo with the biurates of sodium, potassium, ammonium, and magnesium, and some phosphate of calcinm. The proportion of combined to free uric acid is about $:: 1: 4$.

With regard to the relative proportion of the different

81 Vide supra. These analyses seem to be unknown to Dr. Luff, who recently (Pathology and Treatment of Gout, London, 1898, p. 85) gives a partial analysis of a urinary sediment derived from febrile patients, a partial analysis of a urinar

Which we shall consider later. examined ming each fraction, however, to the common stock it was examined microscopically with regard to its uniformity. absence of uric acid, or other crystals, and behaviour with water. If it showed any crystallice constituents (oxalates or phospates, dc.) or falled to give the formation of uric acid crystals upon the addition of water, it was rejected. It is interesting to note that each fraction weighed not more than 0.03 gramme, although originally it had a bulkg appearance. 
metals Table VIIT. will be of interest as giving the result of all the analyses so far published in this connexion ${ }^{33}$ :-

Table VIII.-Relative Lercentage Proportion of Metals in Naturat Urinary Sediments.

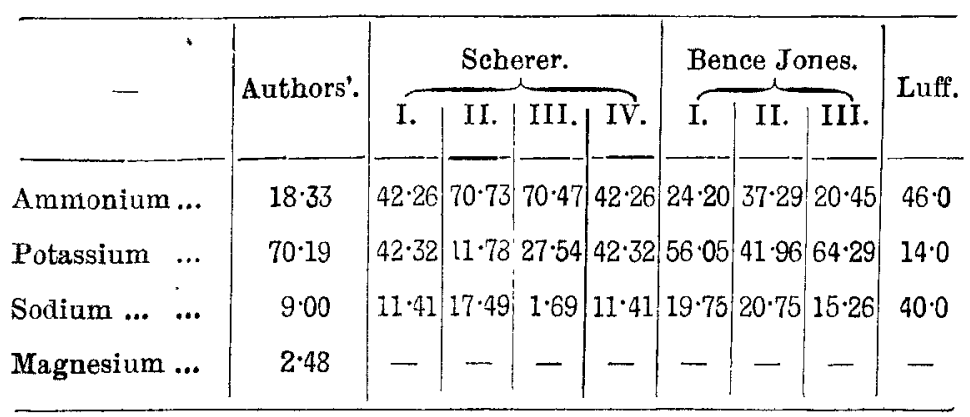

It will be seen from the above table that the proportion of the metals varies in each case. Generally the amount of ammonium is very high. The two exceptions to this are our own analysis and Bence Jones's No. III., which latter also in the proportion of the other bases approaches most nearly to our own. The high ammonium percentage is probably to be explained by decomposition. The same irregularity as in the proportion of the different metals is also evident in the case of the free and combined uric acid (vide supra). Sir William Roberts ${ }^{3 t}$ admits that his analysis, which was not published, of naturally occurring amorphous urinary sediments, gave results discordant with the quadriurate theory. This he explains by decomposition having taken place during the process of collection and to the fact that the sediments were derived from different urines. (In the case of the sediments collected and analysed by us these objections do not apply.) Nevertheless, he assumes that in perfectly natural urine and sediment uric acid exists in the form of a quadriurate. As proof of this be brings forward only one analysis of an artificially prepared, sediment which he regards as the counterpart of the natural one. The process by which he obtained the sediment is essentially the same as the methods described above for the preparation of potassium and sodium quadriurate, except that urine was taken as a solvent instead of water. These experiments we repeated, following exactly Sir William Roberts's directions ${ }^{35}$ (potassium acetate process). Two samples were prepared, different urine being used. Table IX. gives the results of the analysis:-

TABLE IX.-Artificial Urinary Deposits.

\begin{tabular}{|c|c|c|c|c|c|c|c|}
\hline \multirow{2}{*}{ - } & \multicolumn{4}{|c|}{ Analytical numbers. } & \multicolumn{3}{|c|}{ Actual composition. } \\
\hline & \multicolumn{2}{|c|}{ Lot. I. } & \multicolumn{2}{|c|}{ Lot II. . } & Lot & I. & Lot II. \\
\hline & & $\begin{array}{c}\text { Water- } \\
\text { free. }\end{array}$ & - & $\begin{array}{l}\text { Water- } \\
\text { free. }\end{array}$ & 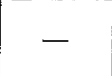 & - & - \\
\hline Total uric acid & 8466 & 8678 & 8726 & $89 \cdot 14$ & Free $\overline{\mathbf{U}}$ & $17 \cdot 47$ & $10 \cdot 17$ \\
\hline Ammonium ... & 033 & 034 & 3.98 & 4.53 & $\mathrm{NH}_{4} \mathrm{U}$ & $3 \cdot 70$ & $49 \cdot 30$ \\
\hline Potassium ... & $9 \cdot 33$ & $9 \cdot 56$ & 3.48 & 3.96 & KH $\overline{\mathrm{U}}$ & $50 \cdot 36$ & $20 \cdot 85$ \\
\hline Sodium $\ldots$... & $3 \cdot 24$ & $3 \cdot 39$ & 2.07 & $2 \cdot 34$ & $\mathrm{NaH} \overline{\mathrm{U}}$ & $23 \cdot 00$ & $19 \cdot 41$ \\
\hline $\begin{array}{l}\text { Water, colour- } \\
\text { ing matter, \&c. }\end{array}$ & $2 \cdot 44$ & - & $12 \cdot 2 i$ & - & - & - & - \\
\hline
\end{tabular}

From this table it will be seen that the precipitate formed under the above conditions is not of constant composition (as is also the case in the normal sediments). The total quantity of the bases as well as their individual amounts vary within wide limits. Further, the quantity of free uric acid is also variable and in neither instance satisfies the quadriurate hypothesis. The relative percentage of the bases and the amounts of free and combined uric acid are given in Table X. The high proportion of potassium in the first analysis is explained by the fact that the urine, derived from the same subject as the urinary sediment analysed above, was originally rich in potassium, which was further increased by the method used (addition of potassium acetate). In the second analysis the urine originally was rich in ammonium.

33 These figures are caiculated from the analysis of the respective authors, with the exception of the last, which is simply copied. 34 Loc. cit., p. 16.
35 Loc. cit., p. 18.
TABLE X.-Relative Percentage Proportion of Metals in Artificial Urinary Sediments.

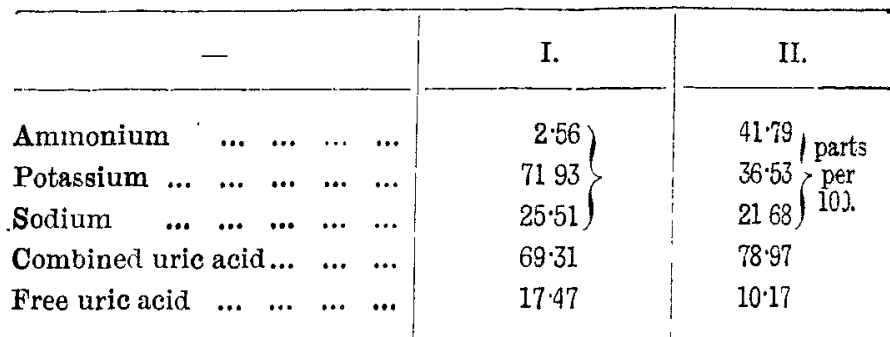

Luff, with the idea of supplementing Sir W. Roberts's analysis of artificial urinary sediment, estimated the metals in a mixed specimen of urinary sediment derived from fever patients. From his results (given above) he draws two definite conclusions. First, that generally the proportion of bases in urinary sediments is that found in his one analysis. This appears to us unjustified in the light of the analytical figures of other observers and our own results given above. Secondly, that the bases are present in the form of quadriurates. This conclusion is still more unjustified in that no estimation of the uric acid was made and thus no ground for his subsequent theoretical calculations exists.

III.

Decomposition bY Water OF Substances Containing

Uric Acid and URates and NeW MeTHOd For Preparing Them.

We have mentioned the characteristic decomposition under the action of water of natural amorphous urinary sediment and the explanation given to this phenomenon by Bence Jones, and subsequently Sir W. Roberts upon the assumption of the existence of a true and definite chemical compound of biurate and uric acid (one molecule of each). Our own experiments have demonstrated that in naturaliy occurring and artificially prepared urinary sediments and urates the aric acid does not occur in this form, and hence that there is no ground for the quadriurate hypothesis. These substances, consisting of mixtures of uric acid and biurates, show under the influence of water the formation of uric acid crystals. $^{36}$ We shall in the future refer to them as decom. posable urates.

The decomposition of these substances by water may best be seen under the microscope. For this purpose it is always advisable to have a relatively large quantity of water. If a very small quantity of the substance be intimately mixed with water on a slide and observed under the microscope, in a very short time the formation of transparent crystals will be seen. These crystals assume either ovoid or rectangular plate form, sometimes intermediate forms are observed, and occasionally the ovoid. shaped crystals pass completely into rectangular plates, probably owing to the influence of the dissolved biurate.

Since the substances showing this decomposition are mixtures of uric acid and biurate as shown by our preceding analyses, this reaction cannot be regarded as characteristic (and as such proving the presence) of quadriurates. ${ }^{37}$ This being the case it should follow that any mixture consisting of biurate and uric acid should show this reaction which must be regarded as the dissolving out by water of the more soluble constituent, biurate, and the leaving behind of the less soluble one, uric acid.

That, however, another factor comes into play is evident from the following experiment. If a mixture in any pro. portion of finely powdered crystalline uric acid and crystalline biurate of sodium be treated with water under the microscope, the dissolving ont of the biurate certainly takes place, but the uric acid remaining behind does not assume the characteristic crystalline form, shown by it when liberated from amorphous decomposable urates. It seems therefore that a necessary factor for this reaction is the presence of uric acid in an amorphous form. This obviously happens in the formation of the decomposable urates by the described methods in which an intimate mixture of uric acid and biurates, both in the amorphous

36 Some of the naturally occurring amorphous urinary sediment examined by us, however, did not show this decomposition with water. This has been observed by Bence Jones and Pfeiffer. Some of the artificially prepared urates consisting as the analysis showed of nearly pure uric acid were also, from obvious reasons, not decomposed in this manner.

37 Sir William Roberts frequently observed that substances not quadriurates showed nevertheless this reaction with water. 
form, is precipitated from solutions by rapid cooling. If we examine more closely the modus operandi of this process we find that the first stage consists in the establishment of a state of equilibrium between the uric acid and the salt in question which gives rise to the formation of biurate in an amount proportional to the original contents of the solution in the salt ; the second stage consists in the saturation of the liquid with uric acid. The amount of this substance taken up (apart from the ordinary physical conditions) depends on the quantity of the salt originally present in the solution. By varying the percentage of the salt corresponding amounts of biurate and uric acid are precipitated on cooling. The precipitate may thus range in composition from pure uric acid to pure biurate. From this it follows that it is possible to hit 8 by accident conditions which will produce a precipitate consisting of uric acid and biurate in equimolecular proportions-i.e., a so-called quadriurate. We succeeded in bringing further proof of the correctness of the above view by preparing decomposable urates by an original method. This consisted in taking solutions saturated at boiling point with biurate and treating the clear filtered solution with an excess of uric acid also at boiling point. Assuming the quadriurates to have the characteristics ascribed to them by Sir William Roberts this method of preparation necessarily excludes their formation in that they are, according to him, decomposed by boiling water. Upon cooling on ice the solution obtained above, an amorphous precipitate was formed which, after filtering, washing, drying, \&c., in the usual way, showed under the microscope the characteristic decomposition. Two samples of the potassium compound prepared in this manner were submitted to analysis. The percentage results are shown in Table XI. :-

TABLe XI.-Artificial Decomposable Potassium Urates.

\begin{tabular}{|c|c|c|c|c|c|c|}
\hline \multirow{2}{*}{ - } & \multicolumn{2}{|c|}{ Analytical figures. } & \multicolumn{4}{|c|}{ Calculated composition. } \\
\hline & I. & II. & & I. & & II. \\
\hline & $\begin{array}{l}\text { Dried at } \\
130^{\circ} \mathrm{C} .\end{array}$ & $\begin{array}{l}\text { Dried in } \\
\text { vac. }\end{array}$ & & & & \\
\hline Total uric acid & $82 \cdot 53$ & $78 \cdot 96$ & - & - & - & - \\
\hline Free uric acid & - & - & $30 \cdot 53$ & - & $31 \cdot 40$ & - \\
\hline $\begin{array}{c}\text { Combined uric } \\
\text { acid } \quad \ldots \quad \ldots\end{array}$ & $11 \cdot 82$ & 10.04 & $11 \cdot 82$ & $\begin{array}{c}\mathrm{KHU} \\
63 \cdot 82 \mathrm{re}- \\
\text { quire } \\
\text { for } \\
1 \mathrm{~mol} . \\
\mathrm{H}_{2} \mathrm{O}\end{array}$ & $47 \cdot 56$ & $\left\{\begin{array}{c}\mathrm{KHU} \\
57 \cdot 60 \mathrm{re}- \\
\text { quire } \\
\text { for } \\
2 \mathrm{~mol} . \\
\mathrm{H}_{2} \mathrm{O}\end{array}\right.$ \\
\hline Water $\ldots \ldots$ & $\frac{5 \cdot 65}{\text { By d }}$ & $10 \cdot 00$ & $5 \cdot 65$ & $5 \cdot 57$ & $10 \cdot 00$ & $10 \cdot 15$ \\
\hline
\end{tabular}

Sample I. was dried at $130^{\circ} \mathrm{C}$. and lost at that temperature 11.00 per cent. of water. This amount corresponds to two molecules of water calculated to the biurate present (calculated 11.16 per cent.) The substance consists of a mixture of uric acid and potassium biurate, the latter holding three molecules of water. Sample II. was dried in vacuo and lost 5.20 per cent. of water corresponding to one molecule of water calculated to the amount of biurate present (calculated 5.12 per cent.). The substance therefore, as in the former case, was a mixture of uric acid and potassium biurate, the latter holding three molecules of water. It will be seen that the potassium biurate moiety of this mixture contains three molecules of water, loses one in vacuo, and one at $130^{\circ} \mathrm{C}$. The last molecule is strongly bound, but appears to be slowly driven off at $150^{\circ} \mathrm{C}$, at which temperature, how-. ever, the substance itself is partly decomposed, assuming a brownish tint. We also prepared the corresponding decomposable sodium urate, ${ }^{39}$ the analysis of which is shown in Table XII.

${ }^{38}$ We presume this is what Sir William Roberts means by "a some what nice adjustment," p. 17, loc. eit.

39 The exact procedure was as follows. Five grammes of crystallised sodium biurate were boiled with 600 eubic centimetres of water, filtered hot; the filtrate was boiled again with five grammes of uric acid. On cooling rapidly on ice a very small quantity of crystalline tric acid at tirst appeared, which was rapidly filtered off. The filtrate gave upon prolonged cooling an amorphous precipitate, which after being filtered and washed in the usual manner, gave the decomposition with water.
TABLE XII.-Artificial Decomposable Sodium Urate.

\begin{tabular}{|c|c|c|c|}
\hline - & $\begin{array}{c}\text { Analytical } \\
\text { figures. }\end{array}$ & \multicolumn{2}{|c|}{ Calculated composition. } \\
\hline Total uric acid & 75.31 per cent. & - & - \\
\hline Free uric acid & - & 13.96 per cent. & - \\
\hline $\begin{array}{c}\text { Combined uric } \\
\text { acid } \quad \ldots \quad \ldots\end{array}$ & - & $61 \cdot 35$ & $\left\{\begin{array}{c}69 \cdot 75 \text { per cent. re- } \\
\text { quire for } 2 \frac{1}{2} \text { mol. of }\end{array}\right.$ \\
\hline Sodium ... ... & 8.40 per cent. & $8 \cdot 40$ & f water. \\
\hline Water $\quad \ldots \quad \ldots$ & $16 \cdot 29$ & $16 \cdot 29$ & 16.44 per cent. \\
\hline
\end{tabular}

The substance lost at $130^{\circ} \mathrm{C}$, 9.80 per cent. of water, corresponding to one and a balf molecules calculated to the amount of biurate present. The substance, therefore, is a mixture of uric acid and biurate of sodium, the latter holding two and a half molecules of water, of which one molecule is retained at $130^{\circ} \mathrm{C}$.

From the preparation and analysis of the above substances it is obvious that artificial mixtures of uric acid and biurate may be obtained which are decomposable by water with the formation of uric acid crystals, and that therefore this behaviour does not prove the presence of a quadriurate.

\section{IV.}

PhYSICO-ChemrCaI OBSERVATIONS ON URIC ACID AND ITS Salts and The Significance of THE SAME.

The now generally accepted constitutional formula of uric acid (first suggested by Medicus ${ }^{10}$ and subsequently definitely established by the researches of $\mathrm{E}$. Fischer ${ }^{41}$ ) is the following :-<smiles>O=C1NC2N[Hg]O[N]C12</smiles>

Although this formula is in accordance with most of the reactions exhibited by this substance it does not provide an explanation of the existence of the now known six monomethyl-uric acids, ${ }^{42}$ nor of its acid nature. A formula, however, fulfilling these requirements (as well as some others into which it is beside our purpose to enter here) is the following:-<smiles></smiles>

which represents a tautomeric form of the acid. These two may be conveniently distinguished as the lactam and lactim formula respectively. According to Fischer the two substances corresponding to the above formulæ actually exist, the amorphous uric acid, as liberated from its salts in cold solution by acids, corresponding to the lactim form. This latter is distinguished from the crystalline form by its property of holding molecularly bound water. The crystals formed gradually from the amorphous acid, through the influence of water on standing, still contain two molecules of water according to the observations of Fritzche ${ }^{43}$ and Matignon. ${ }^{4 \pm}$ These transparent crystals probably represent an intermediary stage between the lactim and lactam forms, still containing two or one $\mathrm{NC}(\mathrm{OH})$ groups. By gentle heat, or on standing over sulphuric acid, they loose these two molecules of water and at the same time their transparency, being completely transformed into the lactam form. ${ }^{45}$ It is the lactim form, however, which explains the salt-forming capacity of the acid.

The uric acids salts also occur in two distinct physical states, namely the amorphous and crystallint. We should explain this by assuming that these two forms are due to the presence of the tautomeric groups, the amorphous (lactim form) containing still two or one $\mathrm{NC}(\mathrm{OH})$ group, the crystalline (lactam form) containing only $\mathrm{NH} . \mathrm{CO}$ groups.

$\$ 0$ Liebig's Annalen die Chemie, 175, 243

41 Bericht der Deutschen Chemischen Gesellschaft, vol. xvii., 1776, \&c. 42 Ibid., vol. xxxii., 2721

43 Journal fuir Praktischer Chemie, 17/56, 1839. 44 Bulletin de la Société Chimique (3), 11, 571, 1894

45 A proof for the lactam formula of the crystalline uric acid might be seen in the behaviour of the dry substance with dry ammonia, unde which conditions, owing to the absence of $\mathrm{OH}$ groups (according to this hypothesis), no salt is formed. Compare Bensch, Liebig's Annalen, 54,201 
This assumption would explain the results of Baumgarten ${ }^{46}$ who observed the transformation of the amorphous sodium biurate (precipitated from saturated solutions of sodium biurate by sodium phosphate or other salts) into the crystalline without any change of chemical composition, except the loss of half a molecule of water. We can confirm Baumgarten's observations in that we prepared sodium biurate in a different way, namely, by dissolving uric acid in weak (from $\frac{1}{2}$ to 1 per cent.) solutions of sodium bicarbonate at boiling point. If such a solution be rapidly cooled amorphous sodium biurate is deposited (spheroids), on slowly cooling, however, the salt comes down in the crystalline form (needles). The former changes into the latter on standing or under the influence of water. Analysis of these two modifications showed that they were both pure biurate of sodium, the amorphous containing (air dry) two molecules the crystalline one and a half molecules of water. The existence of these two forms of urates, the transformation of the one into the other, and the above view with regard to their constitution may have an important chemico-pathological bearing. The extent to which the one must be regarded as physiological and the other as pathological, as well as the study of the conditions under which their transformation takes place in the liquids of the body, may obviously be of interest in gout so far as concerns the physico-chemical basis of this disease.

With regard to the state of uric acid and its salts in solution the following observations and remarks may be of interest. That uric acid is a very weak acid is known. Crystalline uric acid has no influence on moistened litmus paper in the cold. Hot saturated solutions of absolutely pure uric acid, however, show a distinct acid reaction with sensitive litmus and lacmoid. This is explained by the fact that in solutions the acid has the tautomeric form as described above. Uric acid being such a weak acid it is to be expected, according to modern physical chemistry, that its salts would be dissociated in solution. A qualitative proof of this would be that the solution showed an alkaline reaction. The neutral salts actually show a strongly alkaline reaction and are probably therefore dissociated in solution. Heretofore the so-called acid urates have been regarded as possessing a neutral reaction, probably upon the authority of Bentsch, ${ }^{47}$ who first described and analysed them. We found, however, by carefully testing the reaction of solutions of these salts in an absolutely pure state with sensitive indicators that they reacted alkaline. The indicators we made use of were purified sensitive litmus, lacmoid, methyl-orange, Congo red, and rosolic acid. It was possible to show that for instance a solution of sodium biurate containing 1 in 100,000 reacted still distinctly with lacmoid, methyl-orange, and Congo red ${ }^{48}$ A further proof of the dissociation of these urates in dilute solution is the fact that the actual appearance of characteristic uric acid crystals can be observed under the microscope if pure acid urates of potassium or sodium, be treated with a large excess of water. This phenomenon is different from that exhibited by decomposable urates in so far as it requires a longer timefrom half an hour to an hour. These observations require quantitative proof which would probably be afforded by the application of physico-chemical methods (molecular weight estimation in solution, \&c.).

From what we have said above it follows that it is by no means necessary to assume that uric acid circulates in the fluids of the body as a urate, the small quantity present being probably hydroly tically dissociated. Other considerations have led 0 . Minkowski to hold a similar view. ${ }^{49}$ This he expresses as follows: "After all we have no reason to assume that uric acid circulates in the blood as an alkaline compound."

\section{T. CONCLUSIONS}

I. There is no evidence of the existence of a third order of uric acid salts-i.e., quadriurates-either in the artificial or natural amorphous urinary deposits or in the fluids of the body. Under these circumstances we regard it advisable to discontinue the use of the term "quadriurate."

II. The substances obtained artificially under the conditions supposed to produce quadriurates consist of mixtures in

$$
46 \text { Liebig's Annalen, 117, } 109 .
$$

48 In all these tests the reaction exhibited by the salt solution was compared with that shown by an equal volume of pure distilled water and the same indicator.

49 Ernährungstherapie bei Harnsäure-Diathese. V. Leyden's Handbuch der Ernährungstherapie, vol. ii., p. 507 . varying proportions of uric acid and biurates, or of pare uric acid or pure biurates alone.

III. Natural amorphous urinary deposits consist of a mixture of uric acid with urates of sodium, ammonium, potassium, calcium, and magnesium (containing in most cases in addition phosphoric acid).

IV. The property of some natural and artificial amorphous urates of showing the formation of uric acid crystals under the influence of water is due to the dissolving ont of the more soluble biurate moiety and a change in physical state of the remaining uric acid.

V. Any theory concerning the pathology or treatment of gout or the uric acid diathesis built upon the assumption of the existence of quadriurates requires reconsideration.

VI. The existence of two forms of uric acid (the tauto. meric lactam and lactim form) may explain the variation in the physical and physiological behaviour of this acid and its salts.

\section{THE MANAGEMENT OF THE ANAESTHETIC IN CASES IN WHICH RESPIRATORY IMPEDIMENT EXISTS.}

BY DUDLEY W. BUXTON, M.D., B.S., M.R.C.P.LOND,, ANRSTHETIST TO UNIVERSITY COLLEGE HOSPITAL.

IN bringing before this society a communication dealing with certain incidents in surgical anæsthesia I propose to group my remarks about certain cases taken from note. books. The cases which I have selected are those in which from various reasons either anatomical, pathological, or other, interference with respiration occurs. It is clear that if the obstruction exists at the time of giving the anxsthetic and gives evidence of its presence the anæsthetist is placed upon his guard. However, it often happens, as the sequel will show, that although such obstruction exists it does not reveal itself until the progress of anæsthesia introduces a new factor in the problem, while in other cases no obstruction exists as such until the anæsthetic itself leads to its production. All agree that do what we may sooner or later some of us are bound to meet with cases which present symptoms or phenomena in the progress of narcosis which confound our hard-and-fast rules while they jeopardise the lives of our patients. I have arranged some such cases and hope to reason out the causation of the difficulties which they present and to suggest how to obviate serious embarrassments.

As it is important to make my meaning clear it may be well to explain what should be understood by certain phrases. "Primary circulatory failure" may be taken to connote a depression of the circulation which is preceded by no interference with respiration. It is no doubt impossible, speaking physiologically, for any foreign gases or vapour to enter the blood through the epithelium of the lung cells without producing some influence-probably local-upon respiration. It is, I submit, quite possible for marked circulatory depression to arise without there being any apparent anterior respiratory changes of an injurious character. "Secondary circulatory failure" may be taken to mean a circulatory depression consequent upon and causally related to interference with the functions of respiration. It is the respiratory embarrassments which culminate in this secondary circulatory failure with which I propose, to-night, to deal.

There is, I take it, no doubt that the pulmonary circulation is materially assisted or hindered according as (1) the thoracic movements are maintained and are competent; and as (2) the gaseous composition of the blood passing along the veins and arteries of the pulmonary circulation is maintained at its physiological standard. The undue deprivation of oxygen and the excessive venosity of the blood do undoubtedly tell in the direction of impeding the pulmonary circulation and of hampering the efficient and effectual emptying of the heart. Obstruction to respiration may occur at various points and be due to various causes. Let us first consider those arising in the upper air passages. In some the cause is evident, it is well recognised and

1 A paper read before the Harveian Soeiety of London on May 17th, 